\section{INTERNATIONAL STATUS OF CRYSTALLOGRAPHY, PAST AND FUTURE*}

\author{
By Prof. P. P. EWALD
}

$I^{\mathrm{N}}$ $N$ the period between the War of 1914-18 and the beginning of the present War, crystallography experienced a rejuvenation, and in its new form of $\mathrm{X}$-ray crystallography it has once more attained a central position bordering on many fields of promising development. While in its early days crystallography had contacts mainly with mineralogy, geology and crystal optics, at present its most intimate links are with atomic physics, chemistry, metallography and increasingly with engineering and industrial production. In fact, crystallography is forming the background for most problems concerning the solid state of matter. Compared to its advances on the newly won ground, its recent interactions with mineralogy and geology have been rather limited, but this may change in the future. It is recognized that crystallography stands in respect to its methods nearest to physics, for it originated as a part of physics; but the most urgent present demand for its methods and data comes from chemistry.

The early spread of research on crystals from the physical to the mineralogical and chemical laboratories in the first half of the last century prevented a consolidation of crystallography as such. It became, as it were, suspended between the three dominant disciplines. Even to-day, few universities have chairs of crystallography; crystallographic instruction is mostly given in the departments of mineralogy, but the departments of physics and of chemistry usually also give the bare minimum of crystallography which is needed for applications. In no country does there exist a learned society solely for the promotion of interest in, and knowledge of, crystallography. The results of crystallographic research have to be collected from physical, chemical, physico-chemical and mineralogical journals, besides being dispersed in the publications of learned societies. This was so before the days of structural crystallography; since then, biological, engineering and industrial journals have been added to the dispersal area of crystallo. graphic work.

Nevertheless, there is a close connexion between the various sides, pure and applied, of crystallography. The underlying laws and the methods of observation and interpretation are the same, and progress made in one field may immediately benefit problems which seem altogether remote. The determination of unknown crystalline material from geometrical, optical or X-ray observations (to be mentioned again later on) shows the application of different methods to the. same end; while the application of the same method in entirely different fields of research is exemplified by the $\mathrm{X}$-ray deter. mination of particle size and shape of clays, of metals and of catalysts.

The development of other subjects has led to their segregation from their original context. Astronomy and engineering have broken away from physics; physical chemistry, bio- and colloid chemistry from chemistry; there are societies devoted to the promotion of optics and acoustics, with the corresponding journals. This process of specialization, inevitable as

- Part of an evening lecture delivered at the meeting of the X-ray Group of the Institute of Physies at Oxford on March 31, 1944. it seems, is sometimes deplored as a disintegration of science. Should it not rather be looked upon as the formation of a new branch on the tree of science, which conveys the sap to a region hitherto not well provided for, a branch necessary for rounding off the shape of the tree as a whole ? Crystallographic research might gain much by being clearly outlined as such and by being provided for by a Crystallo. graphic Society with its own journal.

This idea is not new, as the history of the Zeitschrift für Kristallographie shows. It was a hundred years of development from Romé Delisle's first correct description of crystals to the foundation of this journal. Even then, in 1877, P. Groth could not venture to devote his journal to crystallography alone, but for financial and other reasons he had to make it a Zeitschrift für Kristallographie und Mineralogie. Fortunately, this foundation coincided with a time of rapid development, especially of chemical crystallography, and the editor, together with the great number of his students from all countries, contributed many important crystallographic papers, thus giving the Zeitschrift a bias towards crystallography. Groth's interest and experience ranged wide and were full of detail. This made his abstracts of crystallographio papers from other publications critical and stimulating, and he aimed at making them detailed enough to render the study of the original papers unnecessary to most readers of the Zeitschrift. From these reviews and from the hundreds of checks and corrections on the reported results which he got his untiring collaborators to carry out, there arose the five volumes of "Chemische Kristallographie", a monumental summary of the first great period of crystallography.

Groth edited fifty-five volumes of his Zeitschrift; then, in 1921, he handed it over to P. Niggli, of Zurich. At the same time a new publisher, the Akademische Verlagsgesellschaft, acquired the Zeitschrift. Niggli remained chief editor until 1940; owing to his not being subjected to the Nazi Reichs. schriftumskammer, and owing to the international connexions of the Zeitschrift, it was possible to maintain for it a freedom in editing which most scientific journals in Germany had to sacrifice in order to survive.

When Niggli took over, the time had at last come when mineralogy could be dropped from the title, which now read Zeitschrift für Kristallographie (Kristallgeometrie, Kristallphysik, Kristallchemie). Many of the papers offered to the Zeitschrift for publication, especially crystal structure determinations, came from abroad, and often after it had been found impracticable to obtain their full publication in the overcrowded physical and chemical journals, the bulk of the readers of which were not interested in the details of the work, or even competent to judge them. The absence of journals devoted to crystallography gave rise to great inconvenience, especially in the English-speaking countries. It was therefore decided to facilitate the publication of structural work in the Zeitschrift by 'internationalizing' it; that is, by accepting papers in French and English as well as in German. At the same time, prominent crystallographers all over the world were asked to act as patrons by allowing their names to figure on the title page and by entrusting the Zeitschrift with the publication of suitable parts of their research. The liberal answer to this request, and the use to which this mode of publication was put, fully justified the action taken. It was somewhat unfortunate that the steady but slow increase in number of subscriptions 
could not balance the rapid increase in volume of production without imposing a heavy burden on the subscribers.

The Zeitschrift für Kristallographie never held, nor attempted to hold, a monopoly in the publication of structural work. Much of this went to the proceedings of learned societies, and much to chemical, physical and technical journals. This will always be so, as it is not easy even to define the class of work which from a rational point of view should go to a journal of crystallography rather than to any related journal. The same di.tculty, however, arises between general and physical chemistry or radio engineering and physics. The decision to publish a particular piece of research in one journal rather than in another depends, apart from more personal grounds, on the nature of the research and on the public which the journal can be expected to reach. The aim of any scientific publication must be to reach those who are most interested in the paper and most competent to judge its merits. The fluidity of the boundaries between subjects is no argument against devoting a journal to any one of them.

The countermeasure to this inevitable centrifugal tendency of scientific publication lies in a reliable abstracting service. Owing to the fact that crystallography is suspended, as it were, between many acknowledged and firmly organized sciences, abstracts of crystallographic papers are to be found in some twenty abstracting journals in English, French and German. But with few exceptions no clear outline of the method and results of these papers can be gained from any one of the abstracts. Groth's ideal of fully summarizing the results quoted in the paper abstracted has been abandoned, and abstracts in most cases merely indicate the type of work presented in the paper.

Various ways were tried in the Zeitschrift of returning to the Groth type of abstract. For the limited field of structure determinations it could be attempted in the 'Strukturbericht', thanks to liberal financial aid given by the Notgemeinschaft der Deutschen Wissenschaft. As regards the entire field of crystallography, however, the attempts failed. Not only was the number of papers so great that the abstractors were unable to keep up with them, but also the variety of the work contained often in a single paper demanded abstracting under different headings and from widely diverging points of view ; finally, the range that had to be covered to satisfy all those interested proved prohibitive from the point of view of cost to the reader. After trying out other systems, a classified collection of titles was all that could be produced. This, however, is very nearly contained in Science Abstracts, Chemical Abstracts, Physikalische Berichte, Zentralblatt, etc.; even if their classification is not quite so convenient as one drawn up for the purposes of crystallography, the gain is not worth paying the price of re-collecting and re-publishing the catalogue of titles.

A similar situation arises in other semi-independent parts of physics and chemistry, such as geophysies or colloid chemistry. It leads to a great amount of duplication of abstracting work. The problem of handling research work from the many points of view, such as methods, results, substances and properties, is so important, and at the same time so diffioult, as to require a concerted effort on the part of all those interested; the methods of approach might well form the subject of further regional and international discussions.
Pending a better solution of this general problem, crystallographic research may best be reviewed and collected by an extension of the method adopted in the Annual Reports of the Chemical Society or in Reviews of Modern Physics. Here no completeness is aimed at, but selected topics are reviewed by particularly competent workers. By changing the subjects of the reports, a fair survey of the whole field is obtained in due course.

Apart from the tasks of publication and abstracting, the development of crystallography after the War of 1914-18 brought some other problems to the fore which required international settlement. The simpler crystal structures had been more or less explored by 1924, and the use of the theory of Schoenflies. Fedorow became imperative. Niggli, Astbury and Yardley, and Wyckoff had adapted this theory to practical requirements, each in their own way, with different origins and axes of the space groups, different symbols in the drawings and different items listed. Text-books which appeared had to choose between two evils: either to repeat all the results, if not the derivation of space groups, or to be quite incomplete for practical work. The preparation of standard tables of space groups was an obvious desideratum. The occasion to discuss it formally arose when, after a conference on crystal structure arranged by the Faraday Society in 1929 , Sir William Bragg convened a meeting of the many crystallographers then present in London. Three committees were set up at this meeting to report (a) on the abstracting scheme, (b) the preparation of tables, (c) nomenclature. Their reports, delivered in the course of the next year, were published in the Zeitschrift für Kristallographie. The Tables Committee, after substantial preparation by correspondence, met in Zurich in 1930 and decided the details of the tables and the distribution of work among the British, American, French, German, Dutch and Swiss authors volunteering for it. These "International Tables for the Determination of Crystal Structures", edited by C. Hermann and published by G. Bornträger in conjunction with firms in the various countries, appeared in 1935, and were subsidized by the International Union of Physics and by many learned societies in the contributing countries. They have since found wide application for structure determinations.

One of the successful innovations in these Tables was the replacement of the conventional Schoenflies notation of space groups by a more rational one, developed by C. Hermann and Ch. Mauguin, which has a direct bearing on the symmetry, and therefore on the actual determination of space groups from X-ray data. Thus the recommendation of the Nomenclature Committee was incorporated in these Tables.

A further occasion for an international discussion was afforded by the International Congress of Physics, held under the auspices of the Union of Physics in London in 1934, one half of which was devoted to problems of the solid state.

No description of international relations in crystallography could overrate the influence of the two great British schools and centres of research, at the Royal Institution, and at the University in Manchester, both associated with the name of Bragg. Here students and scholars from all over the world received training and inspiration for crystallographic work; they made contacts among each other which wove thern into a friendly international guild. 
The present War has temporarily disrupted most of this texture, but it is certain that the desire for even closer international co-operation will return after the War in a subject so wide in extent and developing so quickly. A prelude to this is the regional consolidation of those interested in X-ray crystallography. In the United States, a Society for $X$-ray and Electron Diffraction was founded in 1940 ; its present membership is 350. In Britain, an X-ray Analysis Group of the Institute of Physics was formed in 1943, based on the success of several conferences on the subject which had been arranged by the Institute of Physics in the preceding years and which had shown attendances up to two hundred. In Germany the Deutsche Gesellschaft für technische Röntgenkunde arranged yearly conferences from 1929 onwards which dealt largely with the analysis and testing of materials by means of X-rays. Further regional or national organizations may be in existence or planned in other countries. They are to be welcomed, as they promote the interest taken in the subject, raise the standard of application and form a necessary stepping-stone for an international organization.

The desirability of forming, besides regional crystallographic societies, an International Union of Crystallography, should be clear, I believe, from past experience. Co-operation of all authorities is necessary to develop a subject with so many ramifications and applications to its optimum efficiency. In particular, the following topics seem to demand general agreement :

(1) Publication. It is undesirable that structural and other crystallographic work should be scattered in many journals, each of which only grudgingly concedes adequate space to it. A fair amount of concentration of this work in a single journal offers the obvious advantage of knowing where to look for it.

A journal like Groth's Zeitschrift, privately owned by a publisher, and therefore out of the control of the editors in important respects, is not ideal. It would be preferable to have a journal of crystallography owned by, and edited on behalf of, an International Union of Crystallography.

(2) Archives. The lengthy details of some structural work are of immediate interest only to the very few working on the same or closely related substances. It is unfair to make all the others pay for their publication. On the other hand, it is a generally accepted principle that only public tion of the details allows the necessary check on the author's work. As a way out of this quandary, it has been proposed to establish an archives for crystallography in which the full details submitted to the journal of crystallography would be kept in a form suitable for publication; anyone interested could obtain them at low cost on microfilm or in other photographic form. The manuscripts, as submitted to the editors of the journal, would have to give the complete argument, but on the proposal of the editors or the author certain parts of the details, mainly routine measurements, would be either relegated to the archives and replaced by a summary in the paper, or included in the paper at the author's cost.

These archives would also be used for depositing unfinished work of which only a summary description would appear in the journal.

(3) Abstracts and Summaries of Crystallographic Work. The collection of structural work and of phase diagrams could be carried on in conjunction with the archives and the journal. Summaries of experimental and theoretical work as proposed above could be arranged to appear. An important function of the Union would consist in representing the interest of crystallographers once the general problem of rationalizing the abstracting schemes in science comes to be discussed.

(4) International Tables. The first edition of these Tables is exhausted and a second edition should be prepared by pooling the experiences gained in the various laboratories where they have been in use. It is therefore desirable that the second edition should again be prepared by an international committee. Here also the question of property rights arises; it would be preferable to make the Tables the property of the Union, and to commission a publishing firm with the printing and distribution.

(5) Analytical Tables of Crystals. Various systems have been or are being worked out for determining unknown crystalline substances from geometrical, optical, or X-ray data (cf. J. M. Robertson, Nature, $154,350 ; 1944)$. These systems are still on a tentative scale, but it seems likely that a method of wide applicability will emerge, and with it the necessity for a systematic survey of all known substances. The detailed planning and the distribution of this work would best be done under the auspices of the Union.

(6) General Tasks. Lastly, a Union of Crystallography, represented regionally by its member societies, would act-to use an appropriate metaphor -as a nucleus of crystallization for the whole system of research on the structure and properties of matter in the solid and in related states. The Union and its members would be called upon to co-operate on particular problems with the Unions of Physics and Chemistry, with mineralogical and biological societies, and with those for testing materials. In matters of scientific instruction and of planning of research, the Union might arrive at well-considered recommendations in its field. Finally, the Union might act as a juridical person in matters requiring the handling of money.

A word should be said about the use of the term 'crystallography'. American and British societies referred to earlier have avoided this term in their names and have stressed instead the method of observation they wish to promote. The main reason for this may have been the fact that X-ray and electron diffraction methods are being applied also to substances which are not crystals, such as fibres, proteins, colloids, even liquids and the molecules in gases.

While the titles chosen give a clear indication of the main present activity of the respective societies, I would suggest that they imply a restriction which will ultimately be either abandoned, or prove undesirable. For any particular method, after having been applied for some time, tends either to become a routine method of observation, and as such of minor interest, or continually to be merged with other methods supplementing it from fresh sides. In the case of the X-ray method, this latter happened first when W. L. Bragg drew up a list of atomic radii. Later optical and magnetic observations, and the principles of atomic physics and of crystal chemistry which were being established, were added to the armoury supplementing the diffraction method. For how long will it be true that the main interest of the two societies lies in the diffraction and not in the supplementary methods? Are not many of their members interested mainly in applying the results gained by diffraction methods to the elucidation of 
chemical, mechanical and physical properties ? Is it not one of the main aims of these societies to link up X-ray diffraction with whatever chemical or physical methods seem promising to supplement it? The present circumscription of the societies' activities is decidedly too narrow.

'Crystallography', in its original meaning, does not, it is true, include the entire field of application of diffraction methods. But it covers the main field even then. 'Leptology', which Rinne coined for fine structure ( $\lambda \varepsilon \pi \tau \delta \varsigma$, fine), would be preferable to 'crystallography', but the word has not been generally introduced, and this might not be a good occasion to plead for it. Unless something new is adopted, however, 'crystallography' will have to be used in a wider sense than originally intended, so as to cover substances which for some purposes may be regarded as inferior forms of crystals; in them the arrangement of the atoms or molecules, while showing some kind of regularity, departs further from perfect threedimensional symmetry, homogeneity and periodicity than in the actual piece of quartz to which the name of crystal was originally applied. The remaining regularity may, however, suttce to make profitable a close connexion of substances regarded from this aspect and of the old-time crystals, and it is this enlarged field which the term 'crystallography' should be understood to cover.

\section{'PHENOXETOL' AND OTHER ANTIBACTERIAL SUBSTANCES}

T

$\mathrm{HE}$ offensive against pathogenic micro-organisms continues to succeed, and a number of recent articles upon antibacterial substances indicate the widespread interest in them among non-medical workers and also the value of co-operation between scientific men-and especially biochemists-and the medical man. In a leading article last year the Lancet (781, June 19, 1943) discussed the evaluation of wound antiseptics and directed attention to Prof. Garrod's review of the recent advances that have been made (Brit. Med. Bull., 1, 48; 1943). W. A. Altemeier (Surgery, Gynaec., and Obstetr., 75, No. 6 ; 1942) has published a collective review of the bacteriology of war wounds (see Bull. War Med., 4, 60 ; 1943). Numerous articles in the British Medical Journal and the Lancet keep us continually informed of progress of research on this subject. Referring to the work in Sydney, Australia, of A. Albert, J. E. Falk and S. D. Rubbo (Nature, 153, 712, June 10, 1944), the Lancet (148, July 29, 1944) discusses the antibacterial action of organic arsenicals such as arsphenamine and neoarsphenamine. Interesting also is the work on sulphasuxidine (succinyl sulphathiazole), some of which is hydrolysed in the lower bowel with the release of free sulphathiazole, which is effective in intestinal infections. It is stated in the Lancet (544, April 22, 1944) that E. J. Poth and C. A. Ross (Proc. Amer. Soc. Pharmacol. Fed., Baltimore, 2, 89 ; 1943) claim that sulphathalidine (phthalyl sulphathiazole) is two to four times more bacteriostatic than sulphasuxidine because it is more completely hydrolysed in the bowel. Combinations of sulphathiazole and proflavine in powder form have been recently successfully used by Prof. J. Macintosh and his colleagues (Lancet, 591, May 6, 1944) and by Major G. Y. Feggetter (ibid.; 593). Lieut.-Colonel J. W. Bigger (Lancet, 142, July 29, 1944) records his work on the synergic action of penicillin and the sulphonamides.

Penicillin is, of course, always in the picture. Sir H. W. Florey (Brit. Med. J., 169, Aug. 5, 1944) gives yet another survey of progress of work on its action, and the same issue of that joumal contains articles on the use of penicillin in ophthalmology and in acute empyema and on its combination with sulphonamides for the treatment of infantile gastro-enteritis. J. S. Jeffrey and Scott Thomson (Brit. Med. J., I, July ], 1944) give their experience of the treatment of battle casualties in Italy with penicillin, and in the same issue (p. 15) a leading article discusses an American symposium on the uses of penicillin. In the Lancet (44, July 8, 1944) W. D. Jeans, J. S. Jeffrey and $K$. Gunders record their treatment in Italy of four cases of smallpox with penicillin. The pustules in these cases contained Staphylococcus aureus, and secondary infection must, these authors think, be responsible for much of the toxæmia in the later steges of the disease. The penicillin treatment was followed by marked improvement, and three of the patients survived, including one who had not been vaccinated. Most of the penicillin used in the Mediterranean theatre of war and for research purposes in Great Britain has been supplied by British manufacturers (Brit. Med. J., 186, Aug. 5, 1944), who are now increasing their production of it: but we owe to the United States the solution of its largescale production and the consequent saving of the lives of many British and American wounded.

Penicillin is, of course, active only 8 gainst certain species of bacteria. As Prof. Garrod states (Brit. Med. Bull., ii, 2, 1944), most of the species susceptible to it are Gram-positive, and these include the pyogenic cocei Staphylococcus, Pneumococeus and Streptococcus pyogenes, the gas gangrene group of organisms and those of anthrax and diphtheria. The tubercle bacillus and almost all the Gram-negative bacilli, including the typhoid-dysentery group and Brucella, Homophilus and those common invaders of wounds Proteus and Pseudomonas pyocanea, which produces blue pus, are resistant to penicillin; but the Gram-negative Gonococcus and Meningococcus are susceptible to it. There is great need, therefore (Lancet, i85, Aug. 5, 1944), for a substance which will control Gram-negative organisms. In the same issue of the Lancet (p. 175) is an article by H. Berry on the antibacterial action of ethylene glycol monophenyl ether, to which the name 'Phenoxetol' has been given. Prof. A. A. Miles, in his interesting Sydney Ringer lecture at University College Hospital Medical School on the epidemiology of wound infeetions (Lancet, 809, June 24, I944), points out that Sir Alexander Fleming's work on the bacteriological history of an infected war wound has been abundantly confirmed. Spore-bearing and intestinal coliform bacilli predominate in the first phase; they are replaced by pyogenic cocci in the second phase; and in the third phase these cocci persist and flourish. To them may then be added Pseudomonas pyocyanea and Proteus. Sulphonamides or penicillin will control the cocci, and this is a great advance; but the control of them may enable Ps. pyocyanea and Proteus to become more active, so that healing may be delayed. Berry claims that $P s$. pyocyanea is particularly sus. ceptible to 'Phenoxetol'. The addition of 10-20 per cent of serum in his in vitro experiments with it did not depress its action on this organism, and Berry claims that his in vitro tests suggest that 'Phenoxetol' might perhaps be used with penicillin, the acridine 